THURSDAY, MARCH II, I880

\section{THE RECENT GUNNERY EXPERIMENTS}

W have hitherto refrained from referring to the experiments carried out in December and January last on the 38-ton gun, which was removed from the Thunderer, in the hope that the Heavy Gun Committee would have ere now published their report. The report, however, has not appeared, but in the mean time many most illogical and probably erroneous conclusions have been drawn from the results of the experiments, and circulated amongst the public, apparently with the object of reviving confidence in a system of gun construction, to which, unfortunately, the nation is very deeply committed. These conclusions have latterly been called in question by several competent authorities, notably by Mr. C. W. Merrifield, F.R.S, in an able letter which appeared in the Times of the 8 th inst. We consider it, consequently, to be an opportune moment to draw the attention of our readers to the extremely unscientific manner in which the experiments were carried out, and to the grave danger which may result to the country, from accepting too hastily, the conclusions which have been circulated by those interested in defending the existing system.

As is well known, the trials were instituted in the first instance with the object of testing the verdict of the Committee of Inquiry which was sent to Malta last spring, in order to investigate the cause of the original explosion. It will be remembered that the Committee, in direct opposition to the almost unanimous evidence of the officers and crew of the Thunderer, reported that the explosion was due to double loading. A verdict more extraordinary in the face of the evidence heard was never published, and it naturally met with a perfect storm of criticism. Many independent theories were put forward by outsiders to account for the explosion, so much so, that it was deemed advisable by the War Office authorities to test these theories, and also the verdict of the committee by a series of experiments on the sister gun.

The proper and scientific manner in which to carry out these trials, would have been to have tested each theory separately in an exhaustive manner. Had it been found impossible to burst the gun in this way, there would then no doubt have been a strong probability in favour of the double-loading theory. Instead of this, what was actually done was, first to fire a series of rounds with air spaces between the cartridge and the projectile, which were supposed to have an analogy, but really had none, with the well-known experiment of bursting a fowling-piece by plugging its muzzle with snow or mud. The result of these rounds was well known beforehand to every wellinformed artillerist. Next, two rounds were fired with a papier-mâche wad placed in a slanting position in the bore, some five feet in front of the projectile. This was done with the object of testing Sir William Palliser's theory, that the shot jammed on a partially withdrawn wad, and split open the steel barrel of the gun, in such a manner that the powder gases on reaching the split, blew the gun violently to pieces. It was found in each of these rounds that the wad was blown out of the gun before the shot came near it ; and immediately it was proclaimed that VOL. XXI.--No. 54 t the jamming theory had broken down. The true conclusion to have drawn from these two rounds was, that when wads are placed in the bore of a 38 -ton gun in the manner indicated, that they will be blown out of the gun before the projectile reaches them ; but of what the result would have been, if the wads had been so placed that the projectiles would have jammed on them, these rounds tell us absolutely nothing.

No experiments were made with the object of testing the effect of an accidental crack in the steel barrel, and we all know, that in spite of the utmost care bestowed on the selection of the material, steel gun tubes will crack in the most unexpected manner. Of this we have only this week had a proof in the case of the bursting of a 100-ton gun made for the Italian Government, when the weapon was being fired with the mildest description of powder known to artillerists. In this case the steel tube cracked at the fore shoulder of the chamber, and the gun, incredible though it may sound, being dependent entirely on this tube for its longitudinal strength, parted into two pieces. What the result would have been had British pebble powder been used, which registers 50 per cent. more pressure than the Italian powder which was actually fired, it is easy to see.

Neither was any attempt made to cause the studded projectile to override the rifling, and to ascertain what would have been the result; but it was resolved forthwith to test the effect of double loading. The result was that the gun burst, as most people familiar with its construction supposed it would do. It was immediately loucily proclaimed that the verdict of the committee was correct, and that the Woolwich system was triumphantly vindicated, except for the case-only too likely to occur in action-of the gun being double loaded. Under the circumstance the only proper conclusion to have drawn from this result was, that Woolwich 38 -ton guns will burst when double loaded. But when it is further stated that the two guns burst in totally different manners, it will be at once conceded how utterly groundless such a conclusion was. That the two bursts were totally different ought to have been apparent to the most casual spectator ; for, whereas the first gun was quite uninjured as far as the forward end of the outer breech coil, the second was split from end to end. Moreover the directions of the principal lines of fracture, and the character of the broken fragments were quite different in the two cases. The second was in fact a far more violent explosion than the first one.

One useful lesson might have been learned from the experiment with double-loading, viz., what change this circumstance caused in the powder pressures. But even this chance of obtaining information was missed; for the pressure-gauges were carefully crushed up before the experiment took place, to 36 tons on the square inch, and they failed to record any higher pressure. The fact that the gauges were thus treated, so as to prevent their giving any information as to the pressure required to burst a Woolwich gun, is a most suspicious circumstance, and one which ought to be thoroughly investigated.

Such were the facts, and the only conclusion that can legitimately be drawn from them is, that Woolwich guns are not strong enough to withstand one of the ordinary chances of service. Under these circumstances, it seems to us to be imperatively necessary 
that a new series of experiments should be carried out on a smaller scale, with the object of finding out what other circumstances, in addition to double loading, are likely to cause these weapons to burst, and be a greater danger to friends than to foes. The destruction of the roo-ton gun is not calculated to increase confidence in this combination of steel and iron, especially when it is known that Armstrong and Woolwich guns are built up on almost exactly similar experiments. In addition to testing our own system in an exhaustive manner, guns by other makers should be subjected to exactly the same experiments, and if they yield better results, should be adopted into the service. We have lately seen that Sir William Palliser has subjected an old castiron gun, lined with wrought-iron tubes, on his well-known principle, to the test of double-loading with the most perfect success. Why should not the applicability of his system to guns of the largest calibre be tested? If, as it would appear, artillery officers are incapable of carrying out these experiments in a scientific manner, they should be assisted by outside talent, for the present state of uncertainty ought not to be tolerated for a day longer.

\section{VEGETATION UNDER ELECTRIC LIGHT}

$\mathrm{T}$ HE experiments which Dr. C. W. Siemens has made in growing plants with the illumination of the electric light, and which were laid before the Royal Society at its last meeting, were deservedly received with great interest. In a country where the State does so little in aid of the systematic prosecution of scientific inquiry, it is impossible not to feel something more than appreciative when men like Dr. Siemens bring to its aid the combined resources of wealth and technical knowledge. England is rich in splendid gardens equipped with every horticultural resource. But it is due to the fortunate circumstance that the possessor of such a garden has also paid great attention to the economic applications of electricity, that experiments have been made, on a scale never before attempted, which go a long way towards proving that, as far as vegetation is concerned, all the effects due to solar energy can be artificially produced.

Anything connected with electricity has a peculiar fascination for the public mind, and even in the discussion which took place at the Royal Society, there was not wanting the suggestion that there might be something-a little inscrutable, perhaps-due to the electrical origin of the source of light to which Dr. Siemens had subjected his plants, which exercised an important influence on the results. Such a feeling is of course likely to be still more prominent in the minds of those who have paid no special attention to the processes of plant-life, and who would feel that almost all the interest of the matter was gone if they were asked to eliminate the influence of electricity from it altogether. Yet, obviously, this must be the case directly Dr. Siemens's results are studied in relation with what has already been done in the same direction.

The great physical fact on which all vegetable, and therefore all other life, depends, is the breaking-up of atmospheric carbon-dioxide by the green colouring matter of foliage-chlorophyll, or leaf-green-under the influence of light. How the thing is done is not known; what is known is that it is accomplished by light, and that chlorophyll is the means or instrument by which light is able to effect the dissociation of carbon-dioxide which is the indispensable precursor to the building up by the plant of the various components of its tissues. The plant is in consequence an accumulator of energy, and when its substance is burnt this energy is liberated, and carbondioxide-amongst other things-is again produced.

Now the question which vegetable physiologists have been asking themselves since the beginning of this century is this :- Are these effects producible by light from any source if of adequate intensity, or, as Sachs inquired in 1865 , are they to be attributed to some quality specially inherent in solar light, and which cannot be artificially imitated? It is on this question that the real bearing of Dr. Siemens's experiments is of importance.

Closely connected with the conditions under which the rôte of chlorophyll is performed, are those necessary to its own production. Obviously as the plant grows, its chlorophyll cannot remain a constant quantity; and with some trifling exceptions which do not affect the matter, it may be laid down as an established fact that the same conditions which are essential for the activity of chlorophyll, are also favourable for its manufacture. But it is now known that chlorophyll may be developed under an amount of illumination which is insufficient to bring its functions into play. And this has been the difficulty which the problem has all along presented. In 1806 A. P. De Candolle experimented with the light of six Argand lamps; he found that this was sufficient to develop a green colour in etiolated leaves and also in young seedlings of mustard and cress, but he completely failed to obtain from perfectly healthy foliage any evolution of oxygen, and, therefore, any evidence that carbondioxide had been broken up. In 1860 Biot experimented with a powerful illuminating apparatus (with two Argand burners) which had been constructed for use in measuring an arc of meridian in Spain. This also failed, and it was suggested that the negative result of experiments with lamp-light was attributable to its poorness in rays of high refrangibility. The fact that these are most operative chemically has led many persons to think, on purely $\dot{a}$ priori grounds, that they must play the most effective part in the work done by chlorophyll. But repeated and most careful experiment has shown that this is certainly not the case. A long series of investigations, commencing with those of Daubeny (1836), and taken up successively by Draper (1844), Sachs (1864), and Pfeffer (I87I), have shown without a doubt that the yellow rays are as effective in vegetable nutrition as those of all the rest of the spectrum put together.

The first experiment with the electric light in connection with vegetation was made by Hervé-Mangon in 1861 . He succeeded by means of it in developing chlorophyll in young seedlings of rye, but he did not succeed in demonstrating any chlorophyllian activity by the evolution of oxygen. He found, however, that the electric light possessed one of the characteristic properties of sunlight in producing heliotropism in plants exposed to it. While it is found that the less refrangible rays of the solar spectrum undoubtedly play the most important part in the chemical work which is essential to plant life, the more refrangible rays exercise what may be described as 